\title{
A NEW CLASS OF GENERALIZED NONLINEAR MIXED QUASI-VARIATIONAL INEQUALITIES IN BANACH SPACES
}

\author{
NAN-JING HuANG, YA-PING FANG AND YeOl Je ChO
}

Abstract. In this paper, we introduce and study a new class of generalized nonlinear mixed quasivariational inequalities. Using the KKM technique, we prove the existence and uniqueness of solutions for this class of generalized nonlinear mixed quasi-variational inequalities in reflexive Banach spaces. Our results include the main results of Verma [1], [2] as special cases.

Mathematics subject classification (2000): 47H06, 49J30, 49J40.

Key words and phrases: Generalized nonlinear mixed quasi-variational inequality, Generalized monotone type mapping, Generalized Lipschitz type mapping, the KKM mapping.

\section{REFERENCES}

[1] R. U. Verma, Nonlinear variational inequalities on convex subsets of Banach spaces, Appl. Math. Lett. 10(4) (1997), 25-27.

[2] R. U. VERMA, On monotone nonlinear variational inequality problems, Comment. Math. Univ. Carolinae 39(1) (1998), 91-98.

[3] R. U. VERMA, Nonlinear variational and constrained hemivariational inequalities involving relaxed operators, Z. Angwe. Math. Mech. 77(5) (1997), 387-391.

[4] J. C. YAO, Applications of variational inequalities to nonlinear analysis, Appl. Math. Lett. 4(4) (1991), 89-92.

[5] F. E. BROWDER, On the unification of the calculus of variations and the theory of monotone nonlinear operators in Banach spaces, Proc. Nat. Acad. Sci. U.S.A. 56 (1966), 419-425.

[6] F. E. BROWDER AND W. V. PETRYSHYN, Construction of fixed points of nonlinear mappings in Hilbert spaces, J. Math. Anal. Appl. 20 (1967), 197-228.

[7] E. ZEIDLER, Nonlinear functional analysis and its applications IV, Springer-Verlag, New York, 1988.

[8] N. J. HuANG, Generalized nonlinear variational inclusions with noncompact valued mapping, Appl. Math. Lett. 9(3) (1996), 25-29.

[9] N. J. HuAnG, On the generalized implicit quasi-variational inequalities, J. Math. Anal. Appl. 216 (1997), 197-210.

[10] N. J. HUANG, A new completely general class of variational inclusions with noncompact valued mapping, Comput. Math. Appl. 35(10) (1998), 9-14.

[11] M. A. Noor, Mixed variational inequalities, Appl. Math. Lett. 3 (1990), 73-75.

[12] M. A. Noor, General auxiliary principle for variational inequalities, PanAmerica Math. 4(1) (1994), $27-44$.

[13] A. H. SiddiQI, Q. H. ANSARI AND K. R. KAZMI, On nonlinear variational inequalities, Indian J. Pure Appl. Math. 25(9) (1994), 969-973.

[14] K. FAn, Some properties of convex sets related to fixed point theorem, Math. Annal. 266 (1984), 519-537. 